\title{
What Accounts for Rib Fractures in Older Adults?
}

\author{
Lisa-Ann Wuermser, ${ }^{1}$ Sara J. Achenbach, ${ }^{2}$ Shreyasee Amin, ${ }^{3,4}$ \\ Sundeep Khosla, ${ }^{5}$ and L. Joseph Melton III ${ }^{3,5}$ \\ ${ }^{1}$ Department of Physical Medicine and Rehabilitation, Mayo Clinic, College of Medicine, Rochester, MN 55905, USA \\ ${ }^{2}$ Division of Biomedical Statistics and Informatics, Department of Health Sciences Research, Mayo Clinic, College of Medicine, \\ Rochester, MN 55905, USA \\ ${ }^{3}$ Division of Epidemiology, Department of Health Sciences Research, Mayo Clinic, College of Medicine, Rochester, \\ MN 55905, USA \\ ${ }^{4}$ Division of Rheumatology, Department of Internal Medicine, Mayo Clinic, College of Medicine, Rochester, MN 55905, USA \\ ${ }^{5}$ Division of Endocrinology, Diabetes, Metabolism and Nutrition, Department of Internal Medicine, Mayo Clinic, \\ College of Medicine, Rochester, MN 55905, USA
}

Correspondence should be addressed to L. Joseph Melton III, melton.j@mayo.edu

Received 5 May 2011; Revised 29 July 2011; Accepted 8 August 2011

Academic Editor: Harri Sievänen

Copyright (C) 2011 Lisa-Ann Wuermser et al. This is an open access article distributed under the Creative Commons Attribution License, which permits unrestricted use, distribution, and reproduction in any medium, provided the original work is properly cited.

To address the epidemiology of rib fractures, an age- and sex-stratified random sample of 699 Rochester, Minnesota, adults age 21-93 years was followed in a long-term prospective study. Bone mineral density (BMD) was assessed at baseline, and fractures were ascertained by periodic interview and medical record review. During 8560 person-years of followup (median, 13.9 years), 56 subjects experienced 67 rib fracture episodes. Risk factors for falling predicted rib fractures as well as BMD, but both were strongly age-related. After age-adjustment, BMD was associated with rib fractures in women but not men. Importantly, rib fractures attributed to severe trauma were associated with BMD in older individuals of both sexes. Self-reported heavy alcohol use doubled fracture risk but did not achieve significance due to limited statistical power. Bone density, along with heavy alcohol use and other risk factors for falling, contributes to the risk of rib fractures, but no one factor predominates. Older women with rib fractures, regardless of cause, should be considered for an osteoporosis evaluation, and strategies to prevent falling should be considered in both sexes.

\section{Introduction}

Fractures occur when loads on the skeleton exceed the breaking strength of bone. Among young adults, the skeletal loads causing rib fractures are generally due to high-energy traumatic events. In older adults, rib fractures often result from falls [1, 2], notably among alcoholic patients [3]. However, most fractures in older individuals of both sexes are related also to impaired bone strength, as assessed clinically by bone densitometry [4], and an association between areal bone mineral density (BMD) and rib fracture risk was documented in the Osteoporotic Fractures in Men (MrOS) cohort that was independent of other risk factors [2]. Associations of rib fractures with low bone density have also been observed among older women $[5,6]$, who account for the majority of all fractures in the population, but other potential risk factors have not been addressed in that group. This is an important limitation as interventions for bone loss and for other determinants of fracture risk (e.g., falls) would likely differ. Since rib fractures are associated with significant morbidity, mortality, and cost [7-9], as well as an increased risk of subsequent fractures of other types $[2,10]$, it is important to evaluate the relative impact of bone density versus other contributors to rib fracture risk. We address this issue in an analysis of prospective data from a cohort of women and men randomly sampled from the community.

\section{Materials and Methods}

2.1. Study Subjects. After approval by Mayo Clinic's Institutional Review Board, subjects were recruited from agestratified random samples of Rochester, Minnesota, women 
and men as described in detail previously [11]. Of 348 men who participated and provided full study data, there were approximately 50 subjects per decade of age from 20-29 to 80 years and over (mean age $\pm \mathrm{SD}, 55.4 \pm 19.6$ years; range, 22 to 90 years). Among 351 participating women, there were also about 50 subjects per decade of age, including 138 premenopausal women (age, $35.0 \pm 8.6$ years; range, 21 to 54 years) and 213 women (age, $67.8 \pm 13.2$ years; range, 34 to 93 years) who were postmenopausal ( $\geq 6$ or more months without menses and a follicle-stimulating hormone level $>20$ IU/L) at baseline.

2.2. Risk Factor Assessment. After providing written informed consent, subjects were interviewed by a study nurse using a standard protocol to collect clinical, demographic and lifestyle data. Cigarette smoking and alcohol use were classified as ever/never, while self-reported heavy social or excessive alcohol consumption was considered heavy use. Subjects were also queried about a history of prior fractures, and their complete (inpatient and outpatient) medical records in the community were reviewed by trained nurse abstractors to confirm fracture reports and collect information about a diverse array of conditions predisposing to secondary $\left(2^{\circ}\right)$ osteoporosis (e.g., rheumatoid arthritis, hyperparathyroidism, malabsorption syndrome) or to an increased risk of falling (e.g., stroke, epilepsy, parkinsonism) [12, 13]. Height $(\mathrm{m})$ and weight $(\mathrm{kg})$ were measured, and body mass index (BMI) was defined as $\mathrm{kg} / \mathrm{m}^{2}$. Physical activity (kcal/week) was estimated as described in detail elsewhere [14].

2.3. Bone Densitometry. Areal BMD $\left(\mathrm{g} / \mathrm{cm}^{2}\right)$ was determined for the lumbar spine $\left(\mathrm{L}_{2}-\mathrm{L}_{4}\right.$ in AP projection), femoral neck (FN), and ultradistal radius using dual-energy X-ray absorptiometry (DXA) with the Hologic QDR2000 device (Hologic, Waltham, MA, USA) and software version 5.40. Coefficients of variation (CV) for the spine, hip, and forearm BMD measurements were $0.6 \%, 1.8 \%$, and $0.8 \%$, respectively. Ribs $\mathrm{BMD}$ was obtained from the ribs region of a total body scan on the same instrument.

2.4. Fracture Followup. These subjects were then followed from baseline for the occurrence of any new fracture (prospective cohort study) by periodic interview and review of each subject's medical record at every local medical care provider through 2008. Mayo Clinic records, for example, contain the details of every inpatient hospitalization at its two affiliated hospitals (St. Marys and Rochester Methodist), every outpatient or office visit at the clinic, emergency room, or local nursing homes, as well as all radiographic and pathology reports, including autopsies [15]. The medical records contained the clinical history and the radiologist's report of each rib fracture, but the original X-rays were not available for review. Because we reviewed all local inpatient and outpatient records for each subject, ascertainment of clinically evident fractures is believed to be complete, along with additional rib fractures found incidentally on X-rays taken for other purposes [16]. Recognizing that the actual skeletal loads involved are poorly defined, fractures were attributed to either (1) severe trauma (e.g., high velocity injuries like motor vehicles accidents or falls from a height), (2) no more than moderate trauma (low velocity injuries, by convention, the equivalent of a fall from standing height or less), which encompassed a wide range of presumptive skeletal loads including those rib fractures that appeared to have been "spontaneous" (e.g., secondary to a fit of coughing [17]), or (3) a specific pathological lesion (e.g., metastatic malignancy). In this context, "trauma" is considered synonymous with the forces on bone regardless of the exact nature of the precipitating event.

2.5. Statistical Analysis. The association of rib fractures with $\mathrm{BMD}$ and other potential risk factors was evaluated using two basic methods of analysis, both carried out in SAS (SAS Institute, Cary, NC, USA). The cumulative incidence of a new rib fracture was first estimated for up to 15 years using the Kaplan-Meier method [18]. Andersen-Gill time-to-fracture regression models [19] were then used to assess the impact of various covariates (e.g., BMD, prior fracture history, heavy alcohol use, etc.) on the relative risk (hazard ratio (HR)) of a subsequent rib fracture, separately for women and men. These models allow for multiple rib fracture episodes per subject, while accounting for the correlation structure. The dependent variable was time until rib fracture, and the independent variables were age, $\mathrm{BMD}$, and the clinical characteristics at baseline. For both univariate and ageadjusted models, the assumption of proportional hazards was not violated for the variables considered.

\section{Results}

Baseline characteristics of the 699 subjects are summarized in Table 1. Subsequently, 56 of them had 67 rib fracture episodes (more than one rib could have been fractured in each episode) during 8560 person-years ( $p-y)$ of followup (median, 13.9 years per subject; range, 1 day to 17 years). Forty-six people had a single event, while nine had two and one individual had three separate rib fracture episodes. These included 33 women (9\%) with at least one rib fracture and 23 men $(7 \%)$. Counting episodes, the overall crude incidence of rib fracture was 7.8 per 1000 p-y ( 8.8 per 1000 p-y in women and 6.6 per $1000 \mathrm{p}-\mathrm{y}$ in men), while the estimated cumulative incidence of a rib fracture 15 years after baseline was $9.5 \%$ (10.1\% in women and $9.0 \%$ in men). The median age at the first rib fracture during followup was 83 years for the women and 70 years for the men. The majority (73\%) of rib fractures were due to injuries conventionally attributed to no more than moderate trauma; these included falls from a standing height or less in 23 cases, but no specific traumatic event was acknowledged in nearly $40 \%$ of the episodes, most of which were classified as "spontaneous" (e.g., coughing). The one pathological fracture was due to multiple myeloma. Severe trauma accounted for the remaining fractures (25\%), including 7 rib fractures that occurred as the result of falling from greater than standing height. Of note, $52 \%$ of the women with a rib fracture, as well as $26 \%$ of the men, had at least one traditional osteoporotic fracture (i.e., hip, spine, or distal forearm due to moderate trauma) during followup. 
TABle 1: Characteristics at baseline among 351 Rochester, Minnesota, women and 348 Rochester men followed for rib fracture.

\begin{tabular}{lcc}
\hline Risk factor & Women & Men \\
\hline Age (years), mean \pm SD & $54.9 \pm 19.8$ & $55.4 \pm 19.6$ \\
Prior osteoporotic fracture ${ }^{\ddagger}, \mathrm{N}(\%)$ & $47(13 \%)$ & $36(10 \%)$ \\
Prior rib fracture, N $\%)$ & $20(6 \%)$ & $41(12 \%)$ \\
Alcohol consumption, N (\%) & $299(85 \%)$ & $315(91 \%)$ \\
Heavy alcohol use, N $(\%)$ & $24(7 \%)$ & $66(19 \%)$ \\
Ever smoked cigarettes, N (\%) & $154(44 \%)$ & $27.3 \pm 4.41$ \\
Body mass index $\left(\mathrm{kg} / \mathrm{m}^{2}\right)$ & $26.1 \pm 5.46$ & $30,997 \pm 10,581$ \\
Physical activity $(\mathrm{kcal} /$ week) & $24,534 \pm 7143$ & $134(39 \%)$ \\
Risk factors for 2 ${ }^{\circ}$ osteoporosis, N (\%) & $139(40 \%)$ & $172(49 \%)$ \\
Risk factors for falling, N (\%) & $274(78 \%)$ & $157(46 \%)$ \\
Any fall in past year, N (\%) & $175(50 \%)$ & $0.86 \pm 0.15$ \\
Femoral neck BMD, mean \pm SD & $0.75 \pm 0.15$ & $1.12 \pm 0.18$ \\
Lumbar spine BMD, mean \pm SD & $1.01 \pm 0.16$ & $0.49 \pm 0.08$ \\
Ultradistal radius BMD, mean \pm SD & $0.39 \pm 0.08$ & $0.72 \pm 0.090$ \\
Ribs BMD, mean \pm SD & $0.61 \pm 0.08$ & \\
\hline
\end{tabular}

${ }^{\ddagger}$ Hip, spine, or wrist fracture due to only moderate trauma. BMD, bone mineral density.

$2^{\circ}$, secondary. Note: percents are out of non-missing values.

Rib fracture risk increased with age (HR per 10 years, 1.7; 95\% CI, 1.5-2.0) and was slightly less in men than women $(P=0.331)$. The determinants of a rib fracture varied somewhat by sex, although adjustment for age substantially reduced associations with most risk factors (Table 2). There was a significant age-adjusted association with previous rib fractures in women but not men, as 20 women had experienced a rib fracture prior to baseline compared to only four men. Cigarette use, but not alcohol consumption, was associated with rib fracture risk among the women. However, there was an increased risk of rib fracture episodes with heavy alcohol use among both sexes in the unadjusted analysis. This was not independent of age, although heavy alcohol users (13\% of the cohort) accounted for $24 \%$ of all those with a rib fracture and a third of the subjects with multiple rib fracture episodes. In univariate analyses, greater BMI was protective, while less physical activity increased the risk of a rib fracture. Likewise, diseases associated with a greater likelihood of falling or with secondary osteoporosis, as described in Methods, were associated with an increased risk of rib fracture, but none of these associations was statistically significant after adjustment for age. Among the women but not the men, low BMD at the FN, lumbar spine, and ultradistal radius also predicted an increased likelihood of a rib fracture during followup, as did ribs region BMD from the total body scan. In multivariable analyses, the independent predictors of a rib fracture among the women included age (HR, 1.5; 95\% CI, 1.1-2.1), cigarette smoking (HR, 2.2; 95\% CI, 1.04-4.7), and ultradistal radius BMD (HR 1.8; 95\% CI, 1.1-2.9); among men, age was the only independent risk factor (HR, 1.5; 95\% CI, 1.2-1.9).

Of course, some potentially important variables were correlated. For example, women who smoked were more likely to consume alcohol (94\%) or be heavy alcohol users
(12\%) compared to never smokers (78\% and 3\%, resp.). Likewise, ultradistal radius BMD was highly correlated with FN BMD $(r=0.81 ; P<0.001)$, and the age-adjusted analysis revealed a statistically significant 1.7 -fold overall increase in rib fracture risk per SD decrease in FN BMD among the women. In this group, however, the association was as strong for the $10 \mathrm{rib}$ fractures attributed to severe trauma (HR, 3.0; 95\% CI, 0.9-9.4) as for the $31 \mathrm{rib}$ fractures attributed to no more than moderate trauma (HR, 1.5; 95\% CI, 0.8-2.5), although statistical power was correspondingly limited. Even so, there was a significant 4.6 -fold ( $95 \%$ CI, $1.5-14$ ) increased risk of a severe-trauma rib fracture for each SD decrease in ribs region BMD. No overall age-adjusted association with BMD was observed among the men with rib fractures due to severe trauma, although they were somewhat younger than the women at the time of fracture (median, 60.3 years versus 78.2 years). Among men age 50 years and over, however, each SD reduction in ribs region BMD was associated with a 3.9fold $(95 \%$ CI, $1.2-12)$ increase in the risk of a rib facture attributed to severe trauma.

\section{Discussion}

Despite the fact that they represent the most frequent clinically-evident fracture in older people $[2,20]$, rib fractures have received little attention relative to other common fractures. Rib fractures do appear to be increasing with aging of the population [1]; and, like more traditional osteoporotic fractures [21], the risk of rib fractures increased with age and BMD among randomly sampled women in this prospective study. In this group, the age-adjusted HR per SD decrease in FN BMD was 1.7, consistent with the 1.6-fold increase in rib fracture risk among women in the Study of Osteoporotic Fractures [6], as well as the relative risk of an osteoporotic 
TABle 2: Association of specific risk factors at baseline with subsequent rib fracture risk among 351 Rochester, Minnesota, women and 348 Rochester men.

\begin{tabular}{|c|c|c|c|c|}
\hline \multirow{3}{*}{ Risk factor } & \multicolumn{2}{|c|}{ Women } & \multicolumn{2}{|c|}{ Men } \\
\hline & Unadjusted & Adjusted for age & Unadjusted & Adjusted for age \\
\hline & $\operatorname{HR}(95 \% \mathrm{CI})$ & HR (95\% CI) & $\operatorname{HR}(95 \% \mathrm{CI})$ & $\operatorname{HR}(95 \% \mathrm{CI})$ \\
\hline Age (per 10-year increase) & $1.9(1.5-2.4)^{* * *}$ & - & $1.5(1.2-1.9)^{* * *}$ & - \\
\hline Prior osteoporotic fracture ${ }^{\ddagger}$ (yes, no) & $4.7(2.3-9.5)^{* * *}$ & $2.2(1.1-4.3)^{*}$ & $2.5(0.8-7.6)$ & $1.5(0.5-4.4)$ \\
\hline Prior rib fracture (yes, no) & $5.1(2.2-12)^{* * *}$ & $2.5(1.2-5.3)^{*}$ & $2.1(0.7-6.3)$ & $1.2(0.4-3.6)$ \\
\hline Alcohol consumption (yes, no) & $1.6(0.6-4.4)$ & $2.7(0.98-7.3)$ & $0.8(0.2-3.4)$ & $0.9(0.2-4.4)$ \\
\hline Heavy alcohol use (yes, no) & $2.6(1.01-6.5)^{*}$ & $2.0(0.7-5.9)$ & $2.8(1.2-6.8)^{*}$ & $2.1(0.9-4.7)$ \\
\hline Cigarette smoking (yes, no) & $1.4(0.7-3.0)$ & $2.2(1.04-4.7)^{*}$ & $1.9(0.8-4.4)$ & $1.5(0.7-3.5)$ \\
\hline Body mass index (per unit increase) & $0.9(0.9-1.01)$ & $0.9(0.8-1.01)$ & $1.0(0.9-1.1)$ & $1.0(0.9-1.1)$ \\
\hline Physical activity (per SD decrease) & $2.3(1.3-3.8)^{* *}$ & $1.2(0.7-2.1)$ & $2.1(1.4-3.4)^{* * *}$ & $1.5(0.8-2.8)$ \\
\hline Risk factors for $2^{\circ}$ osteoporosis (yes, no) & $4.1(1.9-8.6)^{* * *}$ & $2.1(0.98-4.5)$ & $2.2(0.98-5.0)$ & $1.2(0.5-2.9)$ \\
\hline Risk factors for falling (yes, no) & $5.6(1.4-23)^{*}$ & $2.1(0.5-8.3)$ & $1.7(0.8-3.9)$ & $0.7(0.3-1.9)$ \\
\hline Any fall in past year (yes, no) & $0.7(0.3-1.4)$ & $1.0(0.5-2.0)$ & $0.8(0.3-1.8)$ & $1.1(0.4-2.7)$ \\
\hline Femoral neck BMD (per 1 SD decrease) & $3.1(2.1-4.7)^{* * *}$ & $1.7(1.05-2.9)^{*}$ & $1.4(0.9-2.1)$ & $1.0(0.7-1.6)$ \\
\hline Lumbar spine BMD (per 1 SD decrease) & $1.9(1.3-2.9)^{* *}$ & $1.2(0.8-1.9)$ & $1.0(0.6-1.8)$ & $1.0(0.7-1.6)$ \\
\hline Ultradistal radius BMD (per 1 SD decrease) & $2.9(2.0-4.3)^{* * *}$ & $1.9(1.2-3.2)^{*}$ & $1.4(0.96-2.2)$ & $1.1(0.7-1.7)$ \\
\hline Ribs BMD (per 1 SD decrease) & $2.3(1.2-4.6)^{*}$ & $1.1(0.6-2.0)$ & $1.5(0.9-2.5)$ & $1.1(0.7-1.8)$ \\
\hline
\end{tabular}

${ }^{* * *} P<0.001 ; * * P<0.01 ; * P<0.05$.

${ }^{\ddagger}$ Hip, spine, or wrist fracture due to only moderate trauma.

fracture (1.6-fold per SD decrease in FN BMD) among white women generally [22]. Somewhat lower relative risk estimates by FN BMD were made in perimenopausal women [23]. Among the men in this study, there was no overall increase in rib fracture risk with lower FN BMD, nor was there any association between rib fractures and FN BMD among men in the Dubbo Osteoporosis Epidemiology Study [24]. This contrasts with a recent report from MrOS, where there was a statistically significant relative rib fracture risk of 1.4 per SD decrease in total hip BMD, even after adjusting for other potential risk factors [2].

Other population-based studies have generally found more rib fractures in men $[16,20,25,26]$, but we found no male excess. Moreover, just $25 \%$ of the rib fractures in our study population were attributed to severe trauma. Noteworthy, however, is the finding that BMD appeared to be as strongly associated with the rib fractures attributed to severe trauma as with those attributed to no more than moderate trauma. It must be recognized, however, that the distinction between "severe" and "moderate" trauma in the bone field is only a convention aimed at countering early criticism that the impact of osteoporosis was exaggerated by including fractures resulting from trauma sufficient to break anyone's bones [27]; the specific forces involved in these different fracture etiologies have not been well quantified. Indeed, even among better studied wrist fractures, which almost invariably are described as caused by "a fall forward on the outstretched arm," the actual orientation of the fall, and presumably the resultant forces, varies substantially [28]. Moreover, other studies have documented the fact that BMD predicts fractures attributed to high trauma events (e.g., motor vehicle accidents) as well as it does to those resulting from presumed lower trauma such as falls [29, 30].

The majority of rib fractures in this study were attributed to lesser degrees of trauma, especially falls from standing height and activities of daily living. Because biomechanical loading (e.g., falling) dominates bone strength with respect to fracture pathogenesis [31], interventions directed solely at improving bone density are unlikely to be completely effective in reducing the fracture burden in the population [32]. In fact, osteoporosis and/or osteopenia only account (i.e., attributable risk) for a quarter of the rib fractures observed among older women in the population [6], so other factors are clearly involved in the etiology. Indeed, body sway was a more important determinant of rib fracture risk than was FN BMD in the Dubbo Osteoporosis Epidemiology Study [24], whereas falling and FN BMD predicted rib fractures comparably among men in the MrOS cohort [2]. In the present investigation, risk factors for falling were somewhat more strongly associated with rib fracture risk than was BMD in the unadjusted analysis. Both variables are strongly age-related, however, and the association with risk factors for falling was not statistically significant after adjusting for age in either sex. One particular risk factor for falling, heavy alcohol use, was associated with a 2-fold age-adjusted increase in rib fracture risk though this did not achieve statistical significance. The relation of bone density to social drinking is equivocal [33], but bone density may be impaired in alcohol abusers [33-35], who are also at increased risk of other fractures $[33,36]$. Nevertheless, only one-quarter of the subjects with rib fractures in this study were considered heavy drinkers so prophylaxis 
focused solely on alcoholism would also be incomplete [37].

This paper has several strengths. In particular, it was a prospective study of randomly sampled community women and men with long followup and superior ascertainment of subsequent fractures. Indeed, fracture ascertainment was likely more complete than for community residents generally [16] since we reviewed all community radiographic reports for each subject. The risk factors were recorded before any knowledge of resultant fractures, and fractures were documented in detailed medical records that spanned each subject's entire period of residency in the community. Our study also has important limitations. The main limitation is the relatively small sample size, with correspondingly low numbers of rib fractures and reduced statistical power. In addition, only $13 \%$ of all subjects reported heavy alcohol use, as such individuals are typically underrepresented in community studies [38]. Also, our results are not generalizable to nonwhites because the study cohort and the underlying Rochester population are largely white [15], although rib fractures appear to be less common in the nonwhite population [39]. Moreover, the local population is largely of Northern European extraction, but age-adjusted hip fracture incidence rates from Rochester are comparable to those for US whites generally [40]. Finally, the focus here is on fractures among older adults. As noted in the Introduction, rib fractures in younger patients often are due to high-energy trauma, and premenopausal women and men under 50 years of age are not generally recommended for osteoporosis assessment [41].

\section{Conclusions}

These limitations notwithstanding, from a clinical perspective, our findings indicate that older women presenting with a rib fracture should generally have a careful evaluation for osteoporosis and be prescribed pharmacologic therapy if appropriate. This is especially important as half of them did not experience a traditional osteoporotic fracture (hip, spine, or wrist) that might otherwise have prompted such a workup. Even those older patients who present acutely in the Emergency Department with fractures resulting from severe ( $\sim$ high velocity) trauma should be followed up with an osteoporosis evaluation as would be expected for women who present with a hip fracture due to a fall. Finally, almost half of all rib fractures observed were precipitated by falls of various types. Consequently, fall prevention strategies should also be considered in both women and men with a rib fracture [42].

\section{Conflict of Interests}

The authors have no relevant conflict of interests and make no disclosures.

\section{Acknowledgments}

The authors would like to thank Brenda Mickow, R.N., Veronica Gathje, R.N., Leona Bellrichard, R.N., Joan LaPlante, R.N., Barbara Nolte, R.N., Kristine Otto-Higgins, R.N., and
Margaret Holets for assistance with data collection and Mary Roberts for help in preparing the paper. This paper was supported by research grant AR27065 from the National Institute of Arthritis, Musculoskeletal and Skin Diseases and made possible by the Center for Translational Science Activities (UL1 RR024150) and the Rochester Epidemiology Project (AG034676 from the National Institute on Aging), US Public Health Service.

\section{References}

[1] M. Palvanen, P. Kannus, S. Niemi, and J. Parkkari, "Hospitaltreated minimal-trauma rib fractures in elderly Finns: longterm trends and projections for the future," Osteoporosis International, vol. 15, no. 8, pp. 649-653, 2004.

[2] E. Barrett-Connor, C. M. Nielson, E. Orwoll, D. C. Bauer, and J. A. Cauley, "Epidemiology of rib fractures in older men: Osteoporotic Fractures in Men (MrOS) prospective cohort study," British Medical Journal, vol. 340, p. c1069, 2010.

[3] Y. Israel, H. Orrego, S. Holt, D. W. Macdonald, and H. E. Meema, "Identification of alcohol abuse: thoracic fractures on routine chest X-rays as indicators of alcoholism," Alcoholism: Clinical and Experimental Research, vol. 4, no. 4, pp. 420-422, 1980.

[4] L. G. Raisz, "Clinical practice. Screening for osteoporosis," New England Journal of Medicine, vol. 353, no. 2, pp. 164-171, 2005.

[5] P. D. Miller, E. S. Siris, E. Barrett-Connor et al., "Prediction of fracture risk in postmenopausal white women with peripheral bone densitometry: Evidence from the National Osteoporosis Risk Assessment," Journal of Bone and Mineral Research, vol. 17, no. 12, pp. 2222-2230, 2002.

[6] K. L. Stone, D. G. Seeley, L. Y. Lui et al., "BMD at multiple sites and risk of fracture of multiple types: long-term results from the Study of Osteoporotic Fractures," Journal of Bone and Mineral Research, vol. 18, no. 11, pp. 1947-1954, 2003.

[7] Y. Barnea, H. Kashtan, Y. Skornick, and N. Werbin, "Isolated rib fractures in elderly patients: mortality and morbidity," Canadian Journal of Surgery, vol. 45, no. 1, pp. 43-46, 2002.

[8] A. Papaioannou, C. C. Kennedy, G. Ioannidis et al., "The impact of incident fractures on health-related quality of life: 5 years of data from the Canadian Multicentre Osteoporosis Study," Osteoporosis International, vol. 20, no. 5, pp. 703-714, 2009.

[9] L. J. Melton 3rd, S. E. Gabriel, C. S. Crowson, A. N. A. Tosteson, O. Johnell, and J. A. Kanis, "Cost-equivalence of different osteoporotic fractures," Osteoporosis International, vol. 14, no. 5, pp. 383-388, 2003.

[10] A. A. Ismail, A. J. Silman, J. Reeve, S. Kaptoge, and T. W. O’Neill, "Rib fractures predict incident limb fractures: results from the European prospective osteoporosis study," Osteoporosis International, vol. 17, no. 1, pp. 41-45, 2006.

[11] L. J. Melton 3rd, C. S. Crowson, W. M. O’Fallon, H. W. Wahner, and B. L. Riggs, "Relative contributions of bone density, bone turnover, and clinical risk factors to long-term fracture prediction," Journal of Bone and Mineral Research, vol. 18, no. 2, pp. 312-318, 2003.

[12] H. Lowe and E. Shane, "Osteoporosis associated with illnesses and medications," in Osteoporosis, R. Marcus, D. Feldman, D. A. Nelson, and C. J. Rosen, Eds., chapter 52, pp. 1283-1305, Elsevier, Amsterdam, The Netherlands, 3rd edition, 2008.

[13] American Geriatrics Society Panel on Falls in Older Persons, "Guideline for the prevention of falls in older persons," Journal 
of the American Geriatrics Society, vol. 49, no. 5, pp. 664-672, 2001.

[14] D. N. Proctor, L. J. Melton 3rd, S. Khosla, C. S. Crowson, M. K. O'Connor, and B. L. Riggs, "Relative influence of physical activity, muscle mass and strength on bone density," Osteoporosis International, vol. 11, no. 11, pp. 944-952, 2000.

[15] L. J. Melton 3rd, "History of the Rochester Epidemiology Project," Mayo Clinic Proceedings, vol. 71, no. 3, pp. 266-274, 1996.

[16] L. J. Melton 3rd, C. S. Crowson, and W. M. O’Fallon, “Fracture incidence in Olmsted County, Minnesota: comparison of urban with rural rates and changes in urban rates over time," Osteoporosis International, vol. 9, no. 1, pp. 29-37, 1999.

[17] V. Hanak, T. E. Hartman, and J. H. Ryu, "Cough-induced rib fractures," Mayo Clinic Proceedings, vol. 80, no. 7, pp. 879-882, 2005.

[18] E. L. Kaplan and P. Meier, "Non-parametic estimation from incomplete observations," Journal of the American Statistical Association, vol. 53, no. 282, pp. 457-481, 1958.

[19] T. M. Therneau and P. M. Grambsch, Modeling Survival Data: Extending the Cox Model, Springer, New York, NY, USA, 2000.

[20] G. Jones, T. Nguyen, P. N. Sambrook, P. J. Kelly, C. Gilbert, and J. A. Eisman, "Symptomatic fracture incidence in elderly men and women: the Dubbo Osteoporosis Epidemiology Study (DOES)," Osteoporosis International, vol. 4, no. 5, pp. 277-282, 1994.

[21] S. R. Cummings and L. J. Melton 3rd, "Osteoporosis I: epidemiology and outcomes of osteoporotic fractures," Lancet, vol. 359, no. 9319, pp. 1761-1767, 2002.

[22] O. Johnell, J. A. Kanis, A. Oden et al., "Predictive value of BMD for hip and other fractures," Journal of Bone and Mineral Research, vol. 20, no. 7, pp. 1185-1194, 2005.

[23] H. Kröger, J. Huopio, R. Honkanen et al., "Prediction of fracture risk using axial bone mineral density in a perimenopausal population: a prospective study," Journal of Bone and Mineral Research, vol. 10, no. 2, pp. 302-306, 1995.

[24] T. V. Nguyen, J. A. Eisman, P. J. Kelly, and P. N. Sambrook, "Risk factors for osteoporotic fractures in elderly men," American Journal of Epidemiology, vol. 144, no. 3, pp. 255-263, 1996.

[25] K. M. Sanders, E. Seeman, A. M. Ugoni et al., "Age- and gender-specific rate of fractures in Australia: a populationbased study," Osteoporosis International, vol. 10, no. 3, pp. 240 $247,1999$.

[26] H. Cooley and G. Jones, "A population-based study of fracture incidence in Southern Tasmania: lifetime fracture risk and evidence for geographic variations within the same country," Osteoporosis International, vol. 12, no. 2, pp. 124-130, 2001.

[27] L. J. Melton 3rd, "Does high-trauma fracture increase the risk of subsequent osteoporotic fracture? Commentary," Nature Clinical Practice Endocrinology and Metabolism, vol. 4, no. 6, pp. 316-317, 2008.

[28] L. J. Melton 3rd, D. Christen, B. L. Riggs et al., "Assessing forearm fracture risk in postmenopausal women," Osteoporosis International, vol. 21, no. 7, pp. 1161-1169, 2010.

[29] K. M. Sanders, J. A. Pasco, A. M. Ugoni et al., "The exclusion of high trauma fractures may underestimate the prevalence of bone fragility fractures in the community: the Geelong Osteoporosis Study," Journal of Bone and Mineral Research, vol. 13, no. 8, pp. 1337-1342, 1998.

[30] D. C. Mackey, L. Y. Lui, P. M. Cawthon et al., "High-trauma fractures and low bone mineral density in older women and men," Journal of the American Medical Association, vol. 298, no. 20, pp. 2381-2388, 2007.
[31] M. L. Bouxsein, "Biomechanics of age-related fractures," in Osteoporosis, R. Marcus, D. Feldman, D. A. Nelson, and C. J. Rosen, Eds., chapter 23, pp. 601-623, Elsevier, Amsterdam, The Netherlands, 3rd edition, 2008.

[32] T. L. N. Järvinen, H. Sievänen, K. M. Khan, A. Heinonen, and P. Kannus, "Shifting the focus in fracture prevention from osteoporosis to falls," British Medical Journal, vol. 336, no. 7636, pp. 124-126, 2008.

[33] K. M. Berg, H. V. Kunins, J. L. Jackson et al., "Association between alcohol consumption and both osteoporotic fracture and bone density," American Journal of Medicine, vol. 121, no. 5, pp. 406-418, 2008.

[34] E. González-Reimers, E. García-Valdecasas-Campelo, F. Santolaria-Fernández et al., "Rib fractures in chronic alcoholic men: relationship with feeding habits, social problems, malnutrition, bone alterations, and liver dysfunction," Alcohol, vol. 37, no. 2, pp. 113-117, 2005.

[35] E. González-Reimers, J. Alvisa-Negrín, F. SantolariaFernández et al., "Vitamin D and nutritional status are related to bone fractures in alcoholics," Alcohol and Alcoholism, vol. 46, no. 2, pp. 148-155, 2011.

[36] K. Laitinen and M. Valimaki, "Bone and the 'Comforts of Life," Annals of Medicine, vol. 25, no. 4, pp. 413-425, 1993.

[37] L. Keso, A. Kivisaari, and M. Salaspuro, "Fractures on chest radiographs in detection of alcoholism," Alcohol and Alcoholism, vol. 23, no. 1, pp. 53-56, 1988.

[38] R. Hasserius, M. K. Karlsson, B. E. Nilsson, I. Redlund-Johnell, and O. Johnell, "Non-participants differ from participants as regards risk factors for vertebral deformities: a source of misinterpretation in the European Vertebral Osteoporosis Study," Acta Orthopaedica Scandinavica, vol. 73, no. 4, pp. 451454, 2002.

[39] M. R. Griffin, W. A. Ray, R. L. Fought, and L. J. Melton 3rd, "Black-white differences in fracture rates," American Journal of Epidemiology, vol. 136, no. 11, pp. 1378-1385, 1992.

[40] L. J. Melton 3rd, A. E. Kearns, E. J. Atkinson et al., "Secular trends in hip fracture incidence and recurrence," Osteoporosis International, vol. 20, no. 5, pp. 687-694, 2009.

[41] NOF Guide Committee, "Clinician's Guide to Prevention and Treatment of Osteoporosis," National Osteoporosis Foundation, 2008, http://www.nof.org/professionals/NOF_Clinicians_Guide.pdf.

[42] P. Kannus and T. L. N. Järvinen, "Falling, not osteoporosis, is the strongest risk factor for rib fracture," British Medical Journal, vol. 340, p. c1069, 2010. 


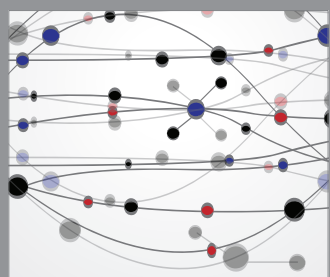

The Scientific World Journal
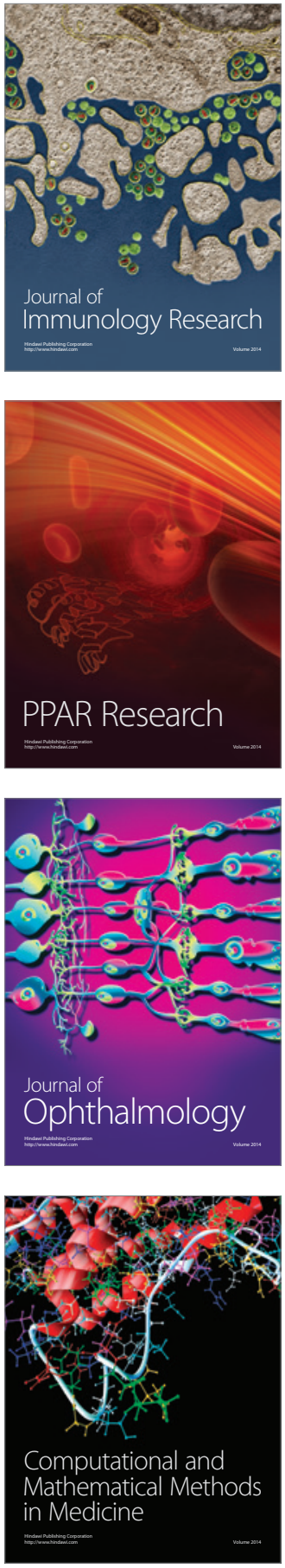

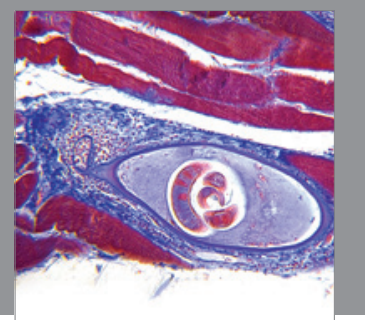

Gastroenterology

Research and Practice
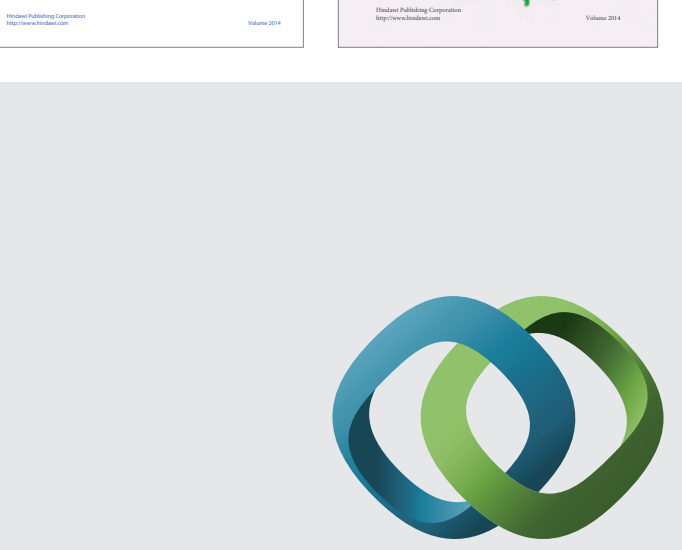

\section{Hindawi}

Submit your manuscripts at

http://www.hindawi.com
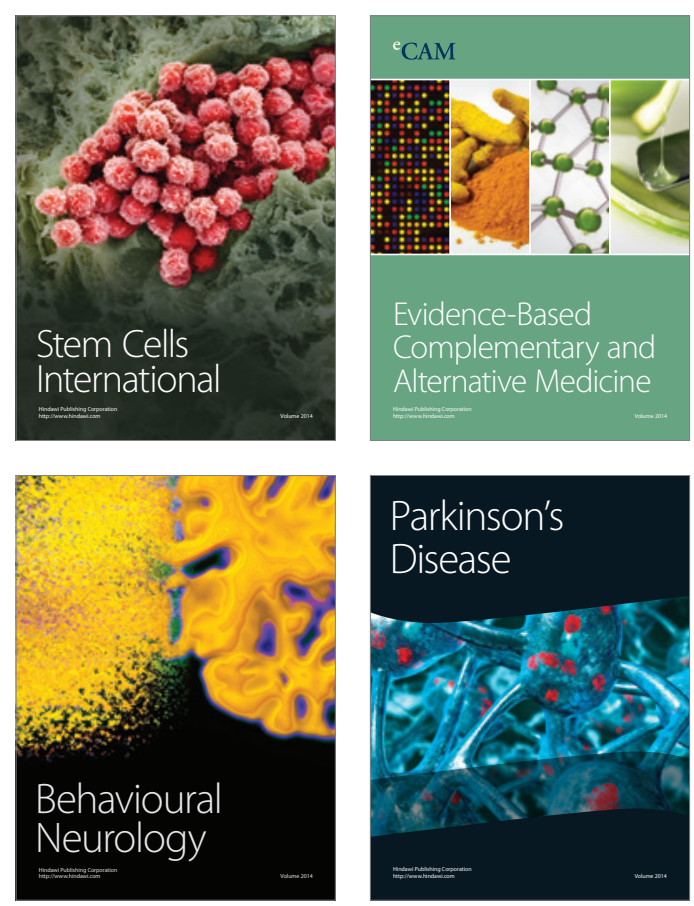

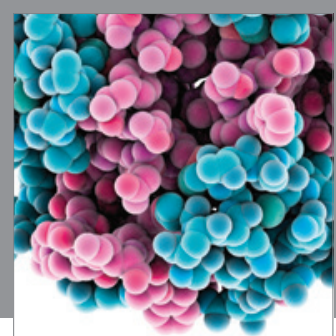

Journal of
Diabetes Research

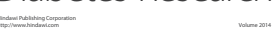

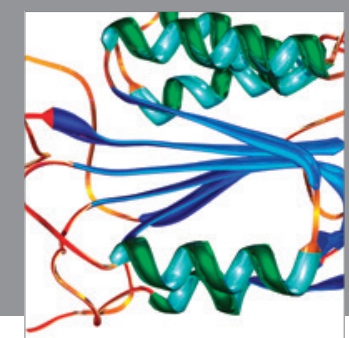

Disease Markers
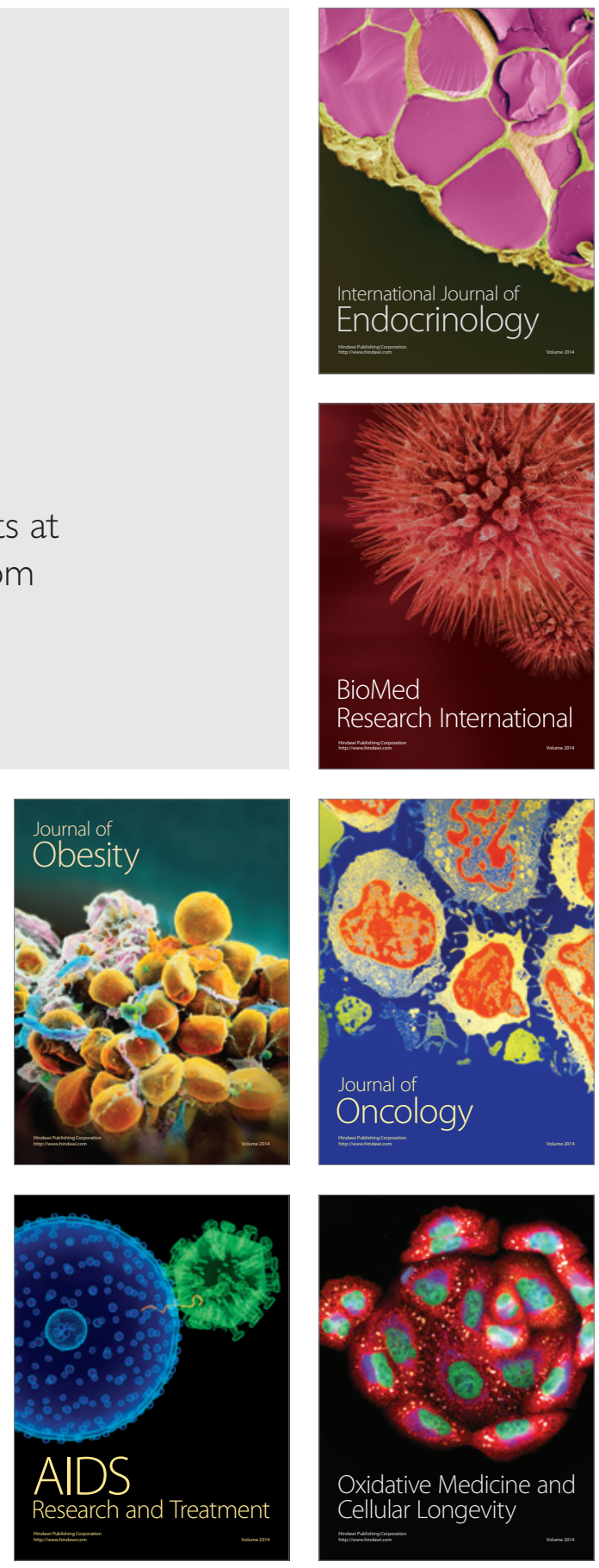